Wp129

\title{
Planning and Running Effective Classroom-Based Exercises*
}

\author{
By \\ Robert D. Woodberry and Howard E. Aldrich \\ Department of Sociology, CB\#3210 \\ University of North Carolina at Chapel Hill \\ Chapel Hill, NC 27599-3210 \\ Phone 919-962-5044 \\ Fax 919-962-7568 \\ Email: bobwood@email.unc.edu \\ Email: howard_aldrich@unc.edu \\ Web Page: http://www.unc.edu/ healdric/
}

*We thank Linda Renzulli and three anonymous reviewers for their helpful comments on previous drafts. 


\title{
Planning and Running Effective Classroom-Based Exercises
}

\author{
ABSTRACT \\ Classroom-based exercises, when used regularly and appropriately, foster many valuable \\ skills. Building on advice scattered across various articles, as well as our own classroom \\ experiences, we offer some general guidelines for planning and running classroom \\ exercises. We focus on planning exercises effectively, communicating these plans to \\ students, and executing them skillfully in the classroom.
}




\section{INTRODUCTION}

Exercises can be an important part of instructors' teaching tool kits. When used regularly and appropriately, they can help students develop critical thinking, teamwork, communication skills, independence, and long-term memory of class concepts (Abrami et al. 1995; Cooper 1996; Cross and Steadman 1996;Dansereau and Johnson 1994; Felder and Brent 1996; Keeley et al. 1995; Qin, Johnson, and Johnson 1995). ${ }^{1}$ They bring sociological ideas alive, allow students to connect sociological concepts with life experiences, and push students to grapple with ethical issues. Exercises work particularly well when they are used within a cooperative learning

framework, ${ }^{2}$ but they can be used with most teaching styles.

Building on previous research and classroom experience, we offer some general guidelines for planning and running effective classroom exercises. We say little about the content of exercises. Instead, we focus on planning them effectively, communicating these plans to students, and executing them skillfully. We hope instructors will review the suggestions in this note when planning exercises and will use also them to analyze their results and seek improvements..

\section{PLANNING SPECIFIC EXERCISES}

We consider two aspects of the planning process: (1) developing a clear plan of action, and (2) preparing instructions for communicating this plan to students.

Developing a Clear Plan of Action and Writing it Down - Instructors should work through exercises carefully to anticipate problems and develop contingency plans. We find it helpful to divide the exercise into discrete steps, visualize what students need to do in each segment, and plan how to move students between parts. Instructors should then write down these instructions for themselves and rehearse them. 
Detailed notes are especially important when instructors are trying a new type of exercise. Their notes should include a hook to grab students' attention, the exact wording of student instructions, whether instructions will be given to students in a handout, on an overhead, or on the board, and how the instructor will divide the students into groups (and of what size). After instructors have run an exercise several times, they can generally reduce their notes to an index card. Lots of detail is important initially so that instructors find possible flaws, but eventually too much detail can be distracting.

Determine the Time Required. For a long exercise, instructors must first decide whether to compress it into one period or to extend it over several periods. To accommodate long exercises, some instructors postpone discussion of results until the next period. However, by then, they often cannot recapture the excitement or insights aroused by the exercise. As Billson (1986) noted, stirring emotions in small groups can heighten their readiness to learn. To benefit from students' heightened emotions and fresh insights, instructors may want to cut back their plans so that the entire unit -- exercise and feedback/discussion -- fits into a single period. Alternatively, instructors may want to break the exercise into a series of freestanding modules that can be conducted and discussed separately.

Time an exercise to maximize its impact. In our experience, starting class with an exercise usually works best. Exercises generally prepare students to participate in discussion or lecture, not visa versa. Plus, exercises typically increase the energy of a class and permit instructors to cover more technical material later. After a lengthy lecture, students' energy is generally low and it is hard to jump-start exercises. Starting class with an exercise also allows students the excitement of discovering things for themselves and leaves sufficient time for debriefing and discussion. 
Break an exercise into segments. Next, instructors should determine the segments of the exercise and plan how they will transition between them (Prescott 1994, 1996). They should decide what they want students to accomplish in each section and which sections are most important. Prioritizing tasks and segments accomplishes three objectives. First, it helps instructors allot time for each part. Second, it helps instructors write directions that focus student attention on key points within each section. Third, it helps instructors know what segments or tasks to cut if one section goes on too long. This prevents classes from wasting time on peripheral tasks and rushing through essential ones.

Structure exercises to be exciting and productive. We suggest three ways instructors can increase students' excitement about exercises and keep them on task. First, get students emotionally involved, perhaps by finding a good hook that piques students' curiosity. For example, before beginning an exercise on the importance of social networks (Giuffre and Paxton 1997), ask students "how did you find your last job?" Have them do novel things or view things in new ways, and when appropriate, get people out of their chairs (Millis 1992). If students are excited, they are more likely to participate actively and stay on task.

Second, maximize student involvement. The more students participate, the more excited they become, and the more they learn (Cross and Steadman 1996:176-77). Therefore, instructors should plan exercises to allow as many students as possible to participate at the same time (Downs-Lombardi 1996). For this reason, pair work and group work are often more effective than class-wide discussions (especially at the start of an exercise). If student groups have to share their conclusions/ideas with the class or other groups, peer pressure helps keep them on task and reminds them of their interdependence (Billson 1986). For example, create a "structured 
controversy" in which all groups must report their position on an important social issue, such as bussing to achieve racial balance in schools (Johnson and Johnson 1979).

Third, give students concrete tasks to complete and a means for assessing their attainment. If appropriate, instructors should ask students to hand in a written product at the end of the exercise. For example, in an exercise on social stratification and inequality, McCammon (1999) asked groups to prepare household budgets for different income groups and report to the whole class. In some cases, instructors can ask each group to turn in a single report or answer sheet. If students have to turn in something, they are more likely to stay on task. For many exercises, formal grading is unnecessary, although students like some indication that the instructor has read it (e.g., checkmarks and underlined key points).

Collecting written products from an exercise has several additional advantages. It helps instructors evaluate students' understanding of concepts from the exercise. Students are often good at hiding their lack of understanding from instructors, but they will have a hard time doing so if they must produce something in writing (Cross and Steadman 1996:20). Collecting work also demonstrates that the instructor takes student insights seriously and provides a regular way to give students feedback. Research shows that this type of regular feedback and interaction with the instructor increases learning and raises students' evaluations of instructors (Cross and Steadman 1996:22-4, 141-53). ${ }^{3}$ Displaying the products generated by students reinforces the notion that some kinds of knowledge are socially constructed and that students can play a productive role in the process.

Prepare Students' Instructions - Instructors must make sure students understand exactly what to do. Otherwise, they waste time asking for help or engaging in fruitless search behaviors, and they may become frustrated and stop participating (Cooper 1990; Downs-Lombardi 1996; 
Prescott 1994, 1996). This is especially important in large classes where professors have less opportunity to answer questions or monitor group participation. We suggest three ways instructors can help students' understand.

Prepare detailed instructions. Keep instructions concrete and specific. For example, it is not sufficient to ask students to "discuss" a topic. Often they will just sit silently and no one will take the lead. Instead, instructors should ask them to carry out specific tasks, such as choosing the best solution from a list of alternatives. For example, in an exercise requiring groups of students to analyze children's games, Glasberg et al. (1998) laid out a specific series of steps that students had to complete: interpret the images on the game boxes, then examine the game boards and playing pieces, and finally play the games. Only after the games were played were students asked to identify the socio-cultural goals of the games. Giving specific directions does not stifle students' creativity, but instead frees them from wasting time on petty details (Prescott 1994).

Organize the exercise visually. Visual displays increase the accessibility of material during exercises and generally enhance learning (Prescott 1994). For example, rather than having students record their results on a blank sheet of paper, give them a chart, a matrix, or two columns with lists of heading and numbers. Instructors can include this in the written instructions, or write it on an overhead and have students copy it.

Use cooperative learning groups. Groups often stall at the beginning if no one takes the lead. Thus, we have found it helpful to divide students into groups at the beginning of the semester, ${ }^{4}$ and assign a leader and secretary for each group. Consequently, students break into groups more quickly and do not waste time building new groups. Each person knows their role and what we expect of them (also see Cooper 1990; Prescott 1992; Johnston 1997a). It also saves time if instructors encourage group members to sit next to each other in class. In fact, this 
generally happens naturally in the evolution of small groups, regardless of instructor prompting (Billson 1986). ${ }^{5}$

\section{EXECUTING THE EXERCISE EFFICIENTLY}

In this section we discuss strategies for implementing exercises. We focus on introducing the exercise, monitoring the flow, and bringing it to an effective close.

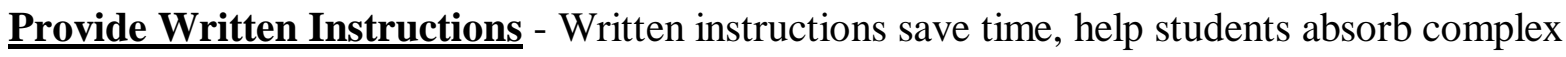
tasks, and allow them to review details of the instructions. If students' minds wander during oral instructions, they will waste time asking others what to do during the time they should be working. ${ }^{6}$

For small classes, we suggest handing out typed instructions to each student or group. Instructors should remain silent while students read the handout. This strategy initially takes more instructor time and resources, but the added clarity makes it worthwhile. Moreover, instructors can reuse typed handouts, whereas they lose whatever they write on the board. If the class is large, instructors can use overheads rather than individual handouts. Writing on the board is slower, harder to read, and tempts instructors to skip or condense steps, thus confusing students.

Monitor and Facilitate the Exercise - Instructors must stay involved in the exercise throughout its execution. Even the best-laid plans can falter if instructors do not coach confused students or adjust to unexpected developments. Instructor involvement shows students that their task is important, and also helps instructors find "teachable moments" they can use in the feedback session. Carry a note card and record observations to be followed up in the general discussion.

Instructors should assess class engagement while walking around and listening to groups. They can check comprehension and prod students to think more deeply. In the short-term, overt 
monitoring occasionally makes students self-conscious and stifles conversation. But most reactions are positive. Students quickly grow accustomed to an instructor sitting down with them to answer questions or offer suggestions. However, this type of monitoring should not be the only method instructors use to keep students on task (especially in large classes). Otherwise, it may only work when they are next to a group.

Monitoring should also be used to adjust time limits. ${ }^{7}$ At the beginning of each exercise section, instructors should announce time limits that they think are the minimum for the task involved. During the exercise, instructors may occasionally remind students of the time remaining. Setting limits helps keep students on task, and also helps instructors evaluate how much to cut from the rest of the class if particular sections take too long. However, flexibility is important. If most groups have not finished by the deadline, instructors can increase the time for a particular section. If most finish early and they seem to have interacted with the material well, instructors can shorten the time slightly (although this should be done more cautiously).

Before instructors close an exercise, they should make sure students have grappled with the material in sufficient depth (Cuseo 1997). ${ }^{8}$ In any case, instructors should not fear ending a section before everyone is finished. A good time to wrap up is when about 70 percent of groups are done. By this time, early groups are still excited and slower groups generally already have something significant to say.

Finishing on time is important, because by the next class period, students' will forget many of their insights and instructors will lose the chance to consolidate or respond to them. Moreover, not finishing on time can mean that the momentum created by the exercise is lost, and trying to regain the excitement of the previous class is difficult. 
Debrief Thoroughly - Every exercise should end with a period of debriefing that covers the goals of the exercise and the value of students' participation in it. First, give students a clear picture of what they have accomplished. Help them see the purpose of the exercise and tie the exercise to the broader goals of the class (Billson 1986; Millis 1997). Moreover, during debriefing, instructors should facilitate higher order thinking by highlighting the multiple perspectives of different individuals and groups.

Debriefing is also an ideal time for students to take notes. If students are anxious about tests and want to write down what they have learned for future review (Panitz 1997), this is an opportunity to accommodate them. Instructors might pause for a few minutes and ask students to write themselves a one page note on what they have learned (see Cross and Steadman 1996:20, 67), or give a mini-lecture on the important points to remember.

Second, emphasize students' contributions to knowledge construction. At the start of the debriefing time, instructors should elicit comments from the groups. In small classes, instructors probably want contributions from every group, but in larger classes or when time is short, not all groups can report. However, each group does not need to report everything they did. After the first few reports, instructors can ask remaining groups to merely add to or critique what others have already said. If instructors solicit comments from only some groups, they should allow different groups to comment the next time.

To emphasize the significance of students' insights, instructors should write down students' comments on the board using their exact words. If instructors must paraphrase to save space, they should ask the student's permission to do so. For example, if a student gives a long answer, instructors might ask them to provide a few words that capture the essence of what they said. After soliciting, recording, and discussing students' contributions, instructors can give their own 
comments and evaluation. However, they should not merely summarize what students have already said. Summaries alone often make students feel they are wasting time or worry that they do not know what the instructor thinks is important. Instructors should put students' contributions into the larger course framework and call attention to connections with previous class topics.

\section{PRACTICE CONTINUOUS IMPROVEMENT}

Instructors should treat each exercise as a learning experiment and look for areas they can improve with the same rigor as they would any research project (Boice 1996). Cross and Steadman (1996) discuss a number of practical ways instructors can do this, and they also provide a guide to various assessment tools.

Get Regular Feedback - One way to obtain feedback is to distribute index cards near the end of the period and ask for comments about the exercise. Instructors should regularly ask for feedback throughout the term, rather than waiting until the end of the semester (Lowman 1995:72-74). This can help instructors adjust their teaching strategies and explain their motivation before problems become serious. Research suggests that if instructors solicit student evaluations and respond to them, subsequent evaluations of the instructor increase dramatically (Cross and Steadman 1996:141-60).

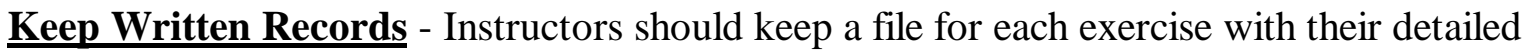
instructions. Immediately after class, instructors should write down what worked and what did not. If they wait too long, their memories will become vague and less useful. For example, if an accidental variation worked, they should note this in the files. If something did not work, they should briefly analyze why and try to think how they could do it better next time. These notes are useful in preparing future classes and continuously improving the exercise. By periodically 
reviewing student feedback and keeping written records, instructors can discover general patterns that improve other exercises and create summaries to share with colleagues and instructors elsewhere.

\section{CONCLUSIONS}

Exercises can be an effective way to increase student motivation and excitement about a subject. They can help both students and instructors learn how well students understand the material, facilitate long-term memory, and foster higher-level thinking skills. Moreover, if instructors regularly conduct exercises based on class readings, students are more likely to come prepared. In this paper, we have offered a number of detailed suggestions on how to plan and conduct exercises effectively.

Of all the principles and suggestions in this paper, we feel that three are particularly important. First, instructors should develop an explicit plan and clearly communicate it to students. Second, instructors should always allow time for debriefing. This allows them to affirm the importance of students' work, bring out key lessons, consolidate those lessons in students' minds, and model critical thinking skills. Third, instructors should obtain regular feedback. Students' opinions, based on their classroom experiences, are an invaluable resource and instructors should not neglect them. 


\section{REFERENCES}

Abrami, Philip C., Bette Chambers, Catherine Poulsen, Christian De Simone, Sylvia D’Apollonia, and James Howden. 1995. Classroom Connections: Understanding and Using Cooperative Learning. Toronto, Canada: Harcourt Brace \& Co.

Billson, Janet Mancini. 1986. "The College Classroom as a Small Group: Some Implications for Teaching and Learning." Teaching Sociology 14:143-51.

Boice, Robert. 1996. First-Order Principles of College Teachers: Ten Basic Ways to Improve the Teaching Process. Bolton, MA: Anker Publishing Co., Inc.

Brent, Rebecca. 1999. "It's a Start.” College Teaching 47:14-17. http://www2.ncsu. edu/unity/lockers/users/f/felder/public/Papers/Getting_started.html

Cooper, Jim. 1990. "Cooperative learning and College Teaching: Tips from the Trenches." The Teaching Professor 4:1-2. 1996. "Research in Cooperative Learning in the Mid-1990s: What the Experts Say." Cooperative Learning and College Teaching 6:2-3.

Creed, Tom. 1996. "Think-Pair-Share-Discuss.” Cooperative Learning and College Teaching 7:4.

Cross, K. Patricia, and Mimi Harris Steadman. 1996. Classroom Research: Implementing the Scholarship of Teaching. San Francisco: Jossey-Bass Publishers.

Cuseo, Joseph B. 1997. "Guidelines for Group Work.” Cooperative Learning and College Teaching 7:11-16.

Dansereau, Don, and David Johnson. 1994. "Cooperative Learning.” Pp. 83-111 in Learning, Remembering, Believing: Enhancing Human Performance, edited by D. Druckman and R. A. Bjork. Washington, D.C.: National Academy Press. 
Downs-Lombardi, Judy. 1996. "Ten Teaching Tips for Newcomers.” College Teaching 44:62-64.

Felder, Richard M. 1997. "Beating the Numbers Game: Effective Teaching in Large Classes," 1997. Proceedings of the Annual American Society for Engineering Education Conference http://www2.ncsu.edu/unity/lockers/users/f/felder/public/Papers/ Largeclasses.html

Felder, Richard M. and Rebecca Brent. 1994. "Cooperative Learning in Technical Courses: Procedures, Pitfalls, and Payoffs.” ERIC Document Reproduction Service, ED 377038. http://www2.ncsu.edu/unity/lockers/users/f/felder/public/Papers/ Coopreport.html . 1996. "Navigating the Bumpy Road to Student-Centered Instruction." College Teaching 44:43-47. http://www2.ncsu.edu/unity/lockers/users/f/felder/ public/Papers/Resist.html

Giuffre, Katherine and Pamela Paxton. 1997. "Building Social Networks," Teaching Sociology 25:207-213.

Glasberg, Davita Silfen, Florence Maatita, Barbara Nangle, and Tracy Schauer. 1998. "Games Children Play: An Exercise Illustrating Agents of Socialization." Teaching Sociology 26:130-139).

Johnson, David W and R. T. Johnson. 1979. "Conflict in the Classroom: Controversy and Learning." Review of Educational Research 49:51-70.

Johnston, Susan. 1997a. "Dangerous Assumptions." Cooperative Learning and College Teaching 7:8-11. 
Kaufman, Deborah B., Richard M. Felder, Hugh Fuller. 1999. "Peer Ratings in Cooperative Learning Teams." Proceedings of the 1999 Annual American Society for Engineering Education Conference http://www2.ncsu.edu/unity/lockers/ users/f/felder/public/Papers/kaufman-asee.PDF

Keeley, Stuart M., Kenneth M. Shemberg, Brenda S. Cowell, and Brian J. Zinnbauer. 1995. "Coping with Student Resistance to Critical Thinking: What the Psychotherapy Literature Can Tell Us." College Teaching 43:140-45.

Lowman, Joseph. 1995. Mastering the Techniques of Teaching ( $2^{\text {nd }}$ ed. $)$. San Francisco: Jossey-Bass Publishers.

McCammon, Lucy. 1999. "Introducing Social Stratification and Inequality: An Active Learning Technique." Teaching Sociology 27:44-54).

Millis, Barbara. 1992. "How Cooperative Learning Can Fulfill the Promise of the 'Seven Principles." Cooperative Learning and College Teaching 2:5-6. . 1997. "Bringing Closure: Some Rapid Report-Out Methods." Cooperative Learning and College Teaching 7:2-3.

Panitz, Ted. 1997. "Faculty and Student Resistance to Cooperative Learning." Cooperative Learning and College Teaching 7:2-4.

Prescott, Susan. 1992. "More Tips for Getting Started with CL.” Cooperative Learning and College Teaching 3:6-7. . 1994. "Trouble-Shooting." Cooperative Learning and College Teaching 5:6-8. . 1996. "Trouble-Shooting." Cooperative Learning and College Teaching 7:5-6. 
Qin, Zhining, David W. Johnson, and Roger T. Johnson. 1995. “Cooperative Versus Competitive Efforts and Problems Solving." Review of Educational Research 65:129-143. 


\section{Appendix: Considerations For Those Who Use Exercises Regularly}

Instructors should be explicit about why they use exercises, especially if they use them often. Most students have little experience with classes that are not lecture-based. Thus, they often assume that the goal of class is to absorb maximum content (or at least transfer it to their notes). Using less class time for lecturing may increase opportunities for student involvement, but it can also raise students' test anxiety because they don't know what they should memorize (Johnston 1997a). Instructors need to explain why they are departing from the traditional lecture method and how students will benefit from the unfamiliar format. For excellent summaries about how to introduce students to cooperative learning strategies see Brent (1996), Cooper (1990), Cross and Steadman (1996:180-1), Felder (1997), Felder and Brent (1994), Keeley (1995), Panitz (1997), and Prescott (1992, 1994, and 1996).

Classroom layout may also be a problem, especially in rooms designed for traditional instructor-centered teaching (e.g., rooms with chairs bolted to the floor). This hampers group discussion and inhibits students from moving between groups or work sites during an exercise. If instructors plan to use exercises regularly and their classrooms do not have moveable chairs, we strongly recommend that they change rooms before the semester begins. Nonetheless, instructors can still conduct exercises such as Think-Pair-Share, or create temporary groups of students seated in adjacent rows (Creed 1996, Felder and Brent 1996).

Finally, using exercises in a large class can be a challenge, but it is a surmountable one. In large classes instructions must be more detailed because the instructor has difficulty answering multiple groups' questions or monitoring when groups stall. Collecting written products may also help keep students on task and help instructors evaluate student comprehension. For more advice on this topic see Felder (1997). 
${ }^{1}$ See http://www.unc.edu/ healdric/soci380/active learn.html for students' comments on the effectiveness of exercises, especially when taught in a course with an active learning format.. ${ }^{2}$ Cooperative learning is an instructional strategy in which small groups work together to produce a common product (Millis 1992). It emphasizes interdependence between group members, individual accountability, high levels of interaction between students, and teachers as facilitators rather than lecturers. ${ }^{3}$ See Cross and Steadman (1996) for other ways to give students regular feedback. Cross and Steadman also assess the impact of regular feedback on student learning.

${ }^{4}$ Cuseo (1997) discusses the advantages and disadvantages of different size groups. Most teachers prefer groups between two and six. Groups from two to four allow greater individual involvement. Groups of four to six allow more diversity of opinion and specialization for complex tasks. For larger groups, designating specific roles is particularly important. For advice on implementing cooperative learning in larger groups, see the Appendix.

${ }^{5}$ For advise on dealing with problems that may develop in group dynamics, see Felder and Brent (1996) and Cross and Steadman (1996).

${ }^{6}$ Research consistently shows that the more time students spend on task, the more they learn and the better evaluations they give their instructors (Cross and Steadman 1996:24).

${ }^{7}$ One way to insure there is sufficient time to debrief at the end of class is to bring a small clock to class and set the alarm to go off ten minutes before the end of the period. Or, better still, instructors can buy a countdown timer that shows how many minutes are left. Some timers have large clock faces that are easy to read unobtrusively. This helps instructors avoid giving students the impression that they are "watching the clock."

${ }^{8}$ If students come to quick superficial answers and then wait passively for the exercise to end, this may be because instructions are vague, the topic uninviting, or because they do not sense the importance of exercises. In such cases, instructors need to reiterate their reasons for using them. If problems develop, note them in your exercise file and contemplate ways to adjust the topic, eliminate ambiguity from instructions, etc. 